\title{
Contents of Journals Relating to Technology and Disability
}

\section{Work, Vol. 6, No. 3, May 1996}

\section{From the Editor}

Multiple sclerosis: Etiology, incidence and prevalence

Health status, work impediments, and coping related to work roles of women with multiple sclerosis

Job placement interventions for people with multiple sclerosis

P.D. Rumrill, Jr., J.M. Steffen, D.A. Kaleta, C.A. Holman (USA)

Factors associated with unemployment among persons with multiple sclerosis

P.D. Rumrill (USA)

Job retention interventions for persons with multiple sclerosis

P.D. Rumrill, J.M. Steffen, G. Sumner (USA)

The role of assessment in enhancing the vocational success of people with multiple sclerosis

R.T. Roessler (USA)

Goal oriented inpatient multiple sclerosis group

Employment and multiple sclerosis: Policy, programming, and research recommendations

Book review

Author index

\section{Journal of Vocational Rehabilitation, Vol. 6, No. 1, April 1996}

Editorial

Introduction

Deaf-blind services in the 21 st century: changing faces and changing service delivery systems

\author{
C.L. Ingraham, C.C. Davis, A. Carey, M. Danek, D. Watson (USA)
}

The state of the evaluation and diagnosis of deaf-blind people: psychological and functional approaches M. Vernon, E. Hammer (USA) 
Cochlear implant for an adult who is deaf-blind: A case study

J. Mascia, V. Silver (USA)

History of congenital rubella syndrome

N. O'Donnell (USA)

The impact of Usher syndrome, type I, on adolescent development

I. Miner (USA)

Adaptive technology for individuals who are deaf-blind

J. Belanich, S. Gelvar (USA)

Orientation and mobility and the Usher syndrome client

J. Cioffi (USA)

\section{Special article}

Agency-sponsored entrepreneurial businesses that employ individuals with psychiatric disabilities:

Findings from a national survey

B. Granger, R.C. Baron (USA)

Book reviews

Rehabilitation research abstracts: Deaf-blindness

Statement by the ILO 